\title{
The Role of Traditional Taboos and Custom as Complementary Tools in Wildlife Conservation Within Mount Cameroon National Park Buea
}

\author{
Ajonina S. Abugiche ${ }^{1}$, Terence O. Egute ${ }^{2}$, Atud Cybelle ${ }^{1}$ \\ ${ }^{1}$ Department of Environmental Science, University of Buea, Buea, Cameroon \\ ${ }^{2}$ Department of Civil \& Public Law with References to the Law of Europe and the Environment, Brandenburg University of Technology \\ Cottbus, Senftenberg, Germany
}

Email address:

Samuel.abugiche@gmail.com (A. S. Abugiche), eguteter@tu-cottbus.de (T. O. Egute), atudcybelle@ymail.com (A. Cybelle)

\section{To cite this article:}

Ajonina S. Abugiche, Terence O. Egute, Atud Cybelle. The Role of Traditional Taboos and Custom as Complementary Tools in Wildlife Conservation Within Mount Cameroon National Park Buea. International Journal of Natural Resource Ecology and Management. Vol. 2, No. 3, 2017, pp. 60-68. doi: 10.11648/j.jinrem.20170203.13

Received: April 29, 2017; Accepted: May 8, 2017; Published: June 7, 2017

\begin{abstract}
This study was carried out to examine the use of traditional taboos and custom in wildlife conservation in the Mount Cameroon National Park. A purposive sampling technique was used in selecting 13 villages from the 41 villages surrounding the park. A total number of 130 respondents were randomly selected for the study and data collected was analyzed using descriptive statistics. From the results, majorities (76.67\%) of the respondents were male and, fall within the age range of 50-59 years $(62.5 \%)$, attained secondary education and $80.83 \%$ were Christians. As the results reveal, a good percentage of the respondents were conversant with cultural practices and its impact in wild animal conservation as $70.83 \%$ and $20.83 \%$ of the respondents strongly agree and agree respectively that cultural practices are used for conserving wildlife species. Religion, migration and westernization were found to be responsible for the decline of cultural practices in wildlife conservation within the study area. One animal, the African forest elephant is reverenced as a deity throughout the study area, although there were taboos forbidding indigenes/residents from killing or eating some particular wildlife species (Chimpanzee, Western bush pig, African python, Preuss monkey, Blue duiker, Drill, African civet, African wild dog, Black kite, White-face owl and snail spp). Illegal communal hunting is still practiced in the area. It is recommended that new and holistic wildlife conservation policies that will blend traditional systems of regulation, myths, rituals, and perceptions with existing wildlife legislation in the country be implemented to enhance conservation in this area.
\end{abstract}

Keywords: Role, Traditional Taboos, Tools, Wildlife Conservation, Mount Cameroon National Park, Buea

\section{Introduction}

According to Tah (2012), a look at the rapid destruction of African traditional conservation practices and the role they played erstwhile in maintaining the ecosystem at equilibrium is fundamental. He argues that the rationale behind modern day wildlife activities is greed, the hunt for more money and hence contradicts the way things were run in the traditional African societies. For some time now, efforts to integrate rural people into biodiversity conservation programs have been in place (Hulme and Murphree, 1999). However, these efforts were largely based on economic incentives (Hulme and Murphree, 1999; Infield and Adams, 1999; Infield, 2002), with little or no attention paid to the role of traditions and taboos in building support for conservation, even though such roles are recognized (Negi, 2010). Traditional knowledge systems play an important role in developing species conservation and management strategies because of the close relationship that exists between cultural diversity and biodiversity (Caldecott et al., 2005; Hens, 2006).

In Africa, there are many studies which suggest that incorporating cultural norms and taboos into conservation programs may provide incentives to communities to conserve natural resources. For instance, in Madagascar, Lingard et al. (2003), Schachenmann (2006), Tengo et al. (2008) and Rabearivony et al (2008) reported the relevance of taboos and traditional laws in the continuous existence of forest biodiversity. Also, studies in Ghana have shown how clans 
protect their natural resources through the use of taboos (Abayie- Boaten, 1998; Hens, 2006; Saj et al., 2006; SarfoMensah and Oduro, 2007; Kobina and Kofi, 2009; Nganje, 2009). Similar cases have also been recorded in Nigeria (Bassey and Kanung, 1996a; Bassey and Kanung, 1996b; Anoliefo et al., 2003; Banjo et al., 2006; Obasohan, 2008; Akindele, 2010; Saka et al., 2012). Moreover, there are also records of effective use of traditional norms and taboos in wildlife conservation in other parts of the world (Gadil et al., 1993; Horowitz, 1998; Mwihomeke et al., 1998; Berkes et al., 2000; Colding and Folke 2001; Berkes 2003; Becker and Ghimire 2003; Moller et al., 2004; Peterson et al. 2007; Kweka, 2004; Kideghesho, 2008; Kassilly and Tsingalia, 2009). These were based on the fact that the practices control human behaviours (Saj et al., 2006; Jimoh et al., 2012). The mount Cameroon region in Central Africa is one of the sites where the equatorial rainforest and its associated wildlife is disappearing at a fast pace due to agricultural activities, poaching and urban development (Joes, 1994). Cameroon's wildlife legislation falls short of reflecting field realities in hunting and wildlife management and does not encourage local hunters to be involved in the management and use of wildlife. This study seeks to identify local practices and institutions, which may promote wildlife conservation; and also the limitations which may affect the efficacy of such institutions and practices as conservation tools.

\section{Methodology}

\subsection{Study Area}

The Park that covers a total of 58,178 hectares and includes the 4,095-metre high Mount Cameroon is surrounded by a total of 41 villages in the South West Region. It lies on the coast, in the Gulf of Guinea, between $3^{\circ} 57^{\prime}$ $4^{\circ} 27^{\prime} \mathrm{N}$ and $8^{\circ} 58^{\prime}-9^{\circ} 24^{\prime} \mathrm{E}$ (MINFOF, 2014). The vegetation of the area is evergreen tropical rain forest (Mbonwoh, 2010). The area is noted for its high species diversity (Reid, 1989; Oates et al., 2004). Debundscha has an incredibly wet climate with an annual rainfall of about 10,299 millimeters (405.5 in) (Frankham et al., 2004). For reasons of easy access and the need to facilitate its administration, Mount Cameroon National Park (MCNP) is spatially divided into four so-called 'cluster conservation zones'. These clusters comprise the 41 villages and zones that make up the Park. They include the Buea cluster in the South and parts of the East, consisting of 13 villages from Upper Boando to Woteva; the Bomboko cluster in the North east and North west areas of the Park, consisting of 12 villages from Bomana to Bova Bomboko; the Muyuka cluster occupying the East and consisting of 9 villages from Ekona Lelu to Munyenge; and the West Coast cluster covering the areas to the West and consisting of 7 villages from Sanje to Lower Boando, (MINFOF, 2014 as can be seen on figure 1 .

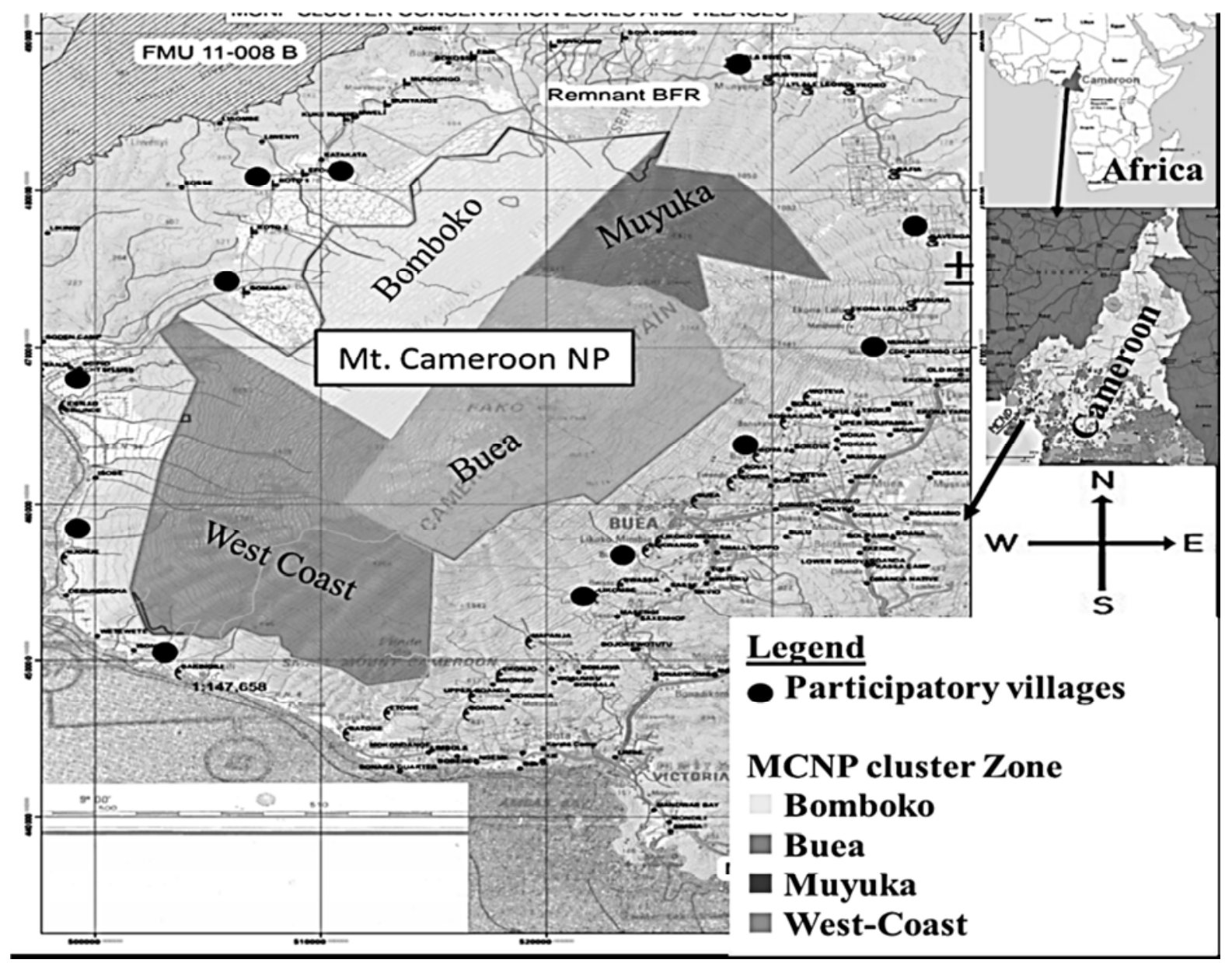

Figure 1. Map of Mount Cameroon National Park (MCNP) showing the cluster conservation zone and study villages. 
It has been increasingly recognized that the forest mass of this valuable ecosystem is challenged by ever-increasing needs for forest products, farmland and nature protection. About 300,000 people live around MCNP, which provides them with large amounts of non-timber forest products, agricultural land, protects their water supplies and shelters sacred sites for many of the communities (MINFOF and WWF, 2014). Mount Cameroon is said to be a biodiversity hotspot, constituting the most diverse ecosystem in Cameroon. According to a 1994 International Union for the Conservation of Nature (IUCN) appraisal, the region is the $10^{\text {th }}$ most conservable place in the world. It harbours the last near isolated and threatened population of the forest elephant. Approximately 45 large and medium-sized (body weight greater than $3 \mathrm{~kg}$ ) mammal species have been recorded around Mount Cameroon and form an important part of the ecosystem. Some of these animals are endemic to the region: the drill (Mandrillus leucophaeus), Preuss's guenon (Cercopithecus preussi), red-eared guenon (Cercopithecus erythrotis) and Mount Cameroon francolin (Francolinus camerunensis). Elephants and chimpanzees are rare and endangered. The carcasses of all of these animals together with some other common species are traded in the area for bushmeat. Monkeys and rodents are the most common Tako, 1999. The mount Cameroon region in Central Africa is one of the sites where the equatorial rainforest and its associated wildlife is disappearing at a fast pace due to agricultural activities, poaching and urban development (Joes, 1994). Cameroon's wildlife legislation falls short of reflecting field realities in hunting and wildlife management and does not encourage local hunters to be involved in the management and use of wildlife. For example, hunting permits are too expensive for local hunters to acquire, especially relative to permits for timber exploitation for artisanal use. Faced with this financial barrier, the local hunters frequently hunt illegally, maximizing their catch in an unsustainable way and killing endangered and tabooed species. The failure of the law to take these field realities into account encourages illegal hunting, which the government is unable to control. It has been very difficult to bring hunters who are not resident in the community to the discussion table. Such hunters enter the area unnoticed, usually abetted by some community members. They transport and sell the catch beyond the villages in neighbouring urban areas like Douala (it will be nice to include the source).

\subsection{Sampling Technique and Data Collection}

Data for this study was collected using structured questionnaire; oral interviews were also conducted with the village elders and chiefs to reduce more information for the study. Site visitations were made where necessary by the research team between November 2012 and June 2013. The method of study is consistent with that reported in literature (Chambers, 1983, 1994). A purposive sampling procedure was adopted in selecting thirteen (13) villages out of the forty one (41) autonomous villages within the MCNP area. Five villages from the Buea cluster and four villages each from the Muyuka and West Coast clusters were randomly selected from three of the four clusters making up the MCNP giving a total of 13 villages. In each of the villages selected, ten (10) households were randomly selected to give a total of 130 households.

\subsection{Data Analysis}

Data obtained were analyzed using descriptive statistics and presented in tables, means, percentages and frequency. This was based on the information provided by the respondents. Furthermore, computer software known as statistical package for social sciences (SPSS) version 19.0 was employed in analyzing the data.

\section{Results}

\subsection{Demographic Characteristics of Respondents}

The result (Table 1) shows that $84.6 \%$ of the respondents were male while $15.4 \%$ were female. This result is obvious as males head majority of the households. The table also shows that majority of the respondents $(36.2 \%)$ fall within the age range of 60 and above years, $29.2 \%$ fall within the age range of 50-59 years while $23.8 \%$ fall within the age range of $40-49$ years and $10.8 \%$ fall within the age range of 30-39 years respectively. This shows that the respondents were matured and should be well informed about traditional taboos and norms of the Bakweri people concerning wildlife species and their conservation in the study area. The educational status of the respondents was grouped into four: Non-formal were those who cannot read and write; primary, those having 1-7 years of elementary formal education; secondary, those having secondary education; and tertiary, those who have attended University or any other higher institution of learning. About $42.3 \%$ of the respondents had secondary education, $37.7 \%$ had primary education, $13.1 \%$ had no formal education and 6.9 had tertiary education respectively. The relatively high educational status of the respondents implies that they have the ability to participate effectively in conservation activities if fully involved. Majority of the respondents (57.7) were engaged in either farming or hunting, $21.5 \%$ were self-employed, while $11.5 \%$ were civil servants and 9.3 were unemployed respectively. Furthermore, majorities (95.4\%) of the respondents were Christians, $3.1 \%$ were Muslims and $1.5 \%$ were traditionalists. This result indicates a very high preference for western religion and abandonment of the traditional African religion and customs. Osemeobo (2009) and Eneji et al. (2012) avowed that increasing exposure of rural communities to imported religions (Christianity and Islam) with different beliefs is crumbling the basis of African mythology on which taboos are based. They stated that Christianity influences the eroding away of African traditional credence and weakens the protection and conservation of sacred forests /groves in Africa. 
Table 1. Demographic characteristics of the respondents.

\begin{tabular}{lll}
\hline Variable & frequency & Percentage \\
\hline Sex & 20 & 15.4 \\
Female & 20 & 15.4 \\
Male & 110 & 84.6 \\
Age & & \\
$30-39$ & 14 & 10.8 \\
$40-49$ & 31 & 23.8 \\
50-59 & 38 & 29.2 \\
60 and above & 47 & 36.2 \\
Educational status & & \\
No formal education & 17 & 13.1 \\
Primary education & 49 & 37.7 \\
Secondary education & 55 & 42.3 \\
Tertiary education & 9 & 6.9 \\
Occupation & & \\
Civil servant & 15 & 11.5 \\
Self employed & 28 & 21.5 \\
Unemployed & 12 & 9.3 \\
Farming/hunting & 75 & 57.7 \\
Religion & & 95.4 \\
Christianity & 124 & 3.1 \\
Islam & 4 & 1.5 \\
Traditionalists & 2 & \\
\hline
\end{tabular}

\subsection{Perceived Impacts of Traditional Taboos and Customs on Wildlife Conservation in MCNP}

The result in (table 2) shows majority $57.7 \%$ and $26.9 \%$ of the respondents strongly agreed and agreed that religion, immigration and improved hunting technology had reduced the impact of traditional taboos and customs as a tool for wildlife conservation in the study area. Furthermore, $15.4 \%$ of the respondents were uncertain of the factors that are responsible for the disrespect of their cultural values and its provision. The vast majority $59.2 \%$ and $33.1 \%$ of the respondents strongly agreed and agreed respectively that wildlife poaching and habitat degradation through deforestation strongly endanger wildlife species in Mount Cameroon National Park. However, the respondents had divided opinions as to whether sacred grooves ensure wildlife conservation and preservation in the Mount Cameroon National Park with $46.2 \%$ strongly agreeing and 29.2 agreeing to this point. Twenty two (22.3\%) of the respondents were unsure and $2.3 \%$ disagreed to this statement. Nevertheless, $61.5 \%$ and $10 \%$ of the respondents were of a strong opinion that traditional taboos and cultural customs can be a powerful tool for wildlife conservation within the park area. Twenty three $(23.1 \%)$ of the respondents were in doubt and $5.4 \%$ disagreed respectively. A majority $36.2 \%$ and $29.2 \%$ respectively of the respondents strongly agreed and agreed that both indigenes and residents do not respect traditional taboos and customs within the study area. On the other hand, $10 \%$ and $20 \%$ respectively strongly disagreed and disagreed with the statement. However, $6.4 \%$ of the respondents were undecided. This indicates that the respect for traditional taboos and its provisions is on the decline in the study area. The consequence of disrespecting these taboos and norms practiced as reported by the respondents is indicated in table 2 . The result shows that majority of the respondents $59.2 \%$ and $33.1 \%$ strongly agreed and agreed that uncontrolled hunting endangers wildlife in the study area.

Table 2. Perceived impacts of traditional taboos on wildlife conservation in MCNP.

\begin{tabular}{|c|c|c|c|c|c|c|}
\hline Variable & $\begin{array}{l}\text { Strongly } \\
\text { disagree }\end{array}$ & Disagree & Unsure & Agree & $\begin{array}{l}\text { Strongly } \\
\text { agree }\end{array}$ & Total \\
\hline $\begin{array}{l}\text { Religion, immigration, improved hunting technology has reduced the } \\
\text { impact of traditional taboos and customs in wildlife conservation }\end{array}$ & $0(0 \%)$ & $0(0 \%)$ & $20(15.4 \%)$ & $35(26.9 \%)$ & $75(57.7 \%)$ & $130(100)$ \\
\hline Illegal hunting and deforestation endangers wildlife species in MCNP & $0(0 \%)$ & $0(0 \%)$ & $10(7.7 \%)$ & $43(33.1 \%)$ & $77(59.2 \%)$ & $130(100)$ \\
\hline Sacred groves ensure wildlife conservation and preservation in MCNP & $0(0 \%)$ & $3(2.3 \%)$ & $29(22.3 \%)$ & $38(29.2 \%)$ & $60(46.2 \%)$ & $130(100)$ \\
\hline $\begin{array}{l}\text { Traditional taboos and practices are used as tools for wildlife } \\
\text { conservation in MCNP }\end{array}$ & $0(0 \%)$ & $7(5.4 \%)$ & $30(23.1 \%)$ & $13(10 \%)$ & $80(61.5 \%)$ & $130(100)$ \\
\hline $\begin{array}{l}\text { Indigenes/residents do not recognize traditional customs and its } \\
\text { practices in MANP }\end{array}$ & $38(10 \%)$ & $26(20 \%)$ & $47(6.4 \%)$ & $13(29.2 \%)$ & $6(36.2 \%)$ & $130(100)$ \\
\hline
\end{tabular}

\subsection{Perceived Traditional Practices and Wildlife Conservation in the Area}

Table 3 shows that $(86.9 \%)$ of the respondents see the African elephant as a sacred or totem animal around the Mount Cameroon region. It was also observed that (94.6\%) of the respondents agreed that the killing of some animals for consumption and other uses although not considered as sacred were forbidden. The result also showed that a majority of respondents $(75.4 \%)$ agreed that traditional taboos and customs are on a decline among the Bakweri people within the study area. A majority (52.3\%) were not of the opinion to integrate traditional taboos and customs into the 1994 national wildlife and forest law. Apart from the forbidden animals, all the respondents (100\%) agreed that communal hunting was still practiced in the area (table 3 ).

Table 3. Perception of respondents on traditional taboos and cultural practices as a tool for wildlife.

\begin{tabular}{|c|c|c|c|c|}
\hline \multicolumn{5}{|l|}{ Conservation in MCNP area. } \\
\hline Variable & Yes & No & Unsure & Total \\
\hline Certain wildlife species such as elephant are treated as totems & $113(86.9 \%)$ & $0(0 \%)$ & $17(13.1 \%)$ & $130(100)$ \\
\hline Some wildlife species are forbidden from consumption and other uses in MCNP area & $123(94.6 \%)$ & $0(0 \%)$ & $7(5.4 \%)$ & $130(100)$ \\
\hline Traditional taboos and custom are declining as years go by among the Bakweri people in & $98(75.4 \%)$ & $16(12.3 \%)$ & $16(12.3 \%)$ & $130(100)$ \\
\hline
\end{tabular}




\begin{tabular}{|c|c|c|c|c|}
\hline \multicolumn{5}{|l|}{ Conservation in MCNP area. } \\
\hline Mount Cameroon area & & & & \\
\hline $\begin{array}{l}\text { Traditional taboos should be incorporated into national law for better conservation of } \\
\text { wildlife in MCNP }\end{array}$ & $40(30.8 \%)$ & $68(52.3 \%)$ & $22(16.9 \%)$ & $130(100)$ \\
\hline Wildlife poaching is still strongly carried out by indigenes/residents in MCNP today & $130(100 \%)$ & $0(0 \%)$ & $0(0 \%)$ & $130(100)$ \\
\hline
\end{tabular}

\subsection{Wildlife Species Forbidden to Be Killed or Eaten}

Ten mammal, two birds and snail species were mentioned as forbidden by respondents, either for reasons of food or cultural taboo, religion, personal dislike or on health grounds within the study area. Sixty nine (69\%) of the respondents cited taboo as for not killing or consuming any of the thirteen species mentioned, whereas $21 \%, 8 \%$ and $2 \%$ respectively were for reasons ranging from personal dislike, health and religion. With exception of Bakwerians from Bota land and Wuvia who believe that the high speed at which the blue duiker runs causes madness and therefore prohibited its killing and consumption, Bakwerians from all other villages in the study area eat the animal. However, all $(100 \%)$ of the respondents within the study villages in the Buea, Muyuka and West Coast clusters of the park strongly agreed that the African elephant (Loxodonta africana) is prohibited in all forms from killing and consumption by the Bakweri custom and is a strong tabooed animal within the Mount Cameroon area.

Other wildlife species prohibited in the communities included the Chimpanzee, Western bush pig, African python, Blue duiker, Drill, Monkey spp, African Civet, African wild dog, Black Kite and the White-Face Owl (table 4).

Table 4. Animals with taboos attached to their killing and consumption by the Mokpwe (Bakweri) people of MCNP area.

\begin{tabular}{lll}
\hline Common Name & Scientific name & Mokpe name \\
\hline Forest elephant & Loxodonta africana & N'joku \\
Chimpanzee & Pan troglodytes & Ewaki \\
Western bush pig & Potamochoerus porcus & Ngowa wanga \\
African python & Python sebac & Mohzo \\
Preuss monkey & Cercopithecus preussi & Lingote \\
Blue duiker & Cephalophus monticola & Mbweya \\
Drill & Papio leucophaeus & Sumbo \\
African Civet & Viverra civetta & Njuwe \\
African wild dog & Lycaon pictus & ezso \\
Black Kite & Milvus migrans & Wombe \\
White-Faced Owl & Ptilopsis leucotis & ezu \\
Monkey spp & - & Lingote \\
Snail & Achachantina spp & Nyamangoro \\
\hline
\end{tabular}

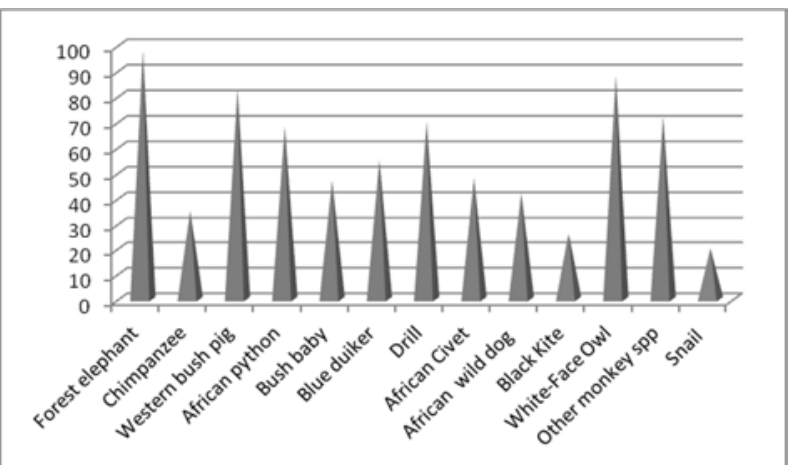

Figure 2. Classification of some wildlife species according to strength of taboo in MCNP area.
The strongest reason advanced for not killing or consuming most of the prohibited species was due to food or cultural taboo with majority $96.69 \%$ of respondents strongly agreeing to the statement. Whereas $30.21 \%$ of the respondents loathe the species and so did not kill nor consumed them. $11.8 \%$ of the respondents did not kill or consume the species because of health reasons while $3.2 \%$ of the respondents said their religious belief make them not to kill or consume the species (figure 3 ).

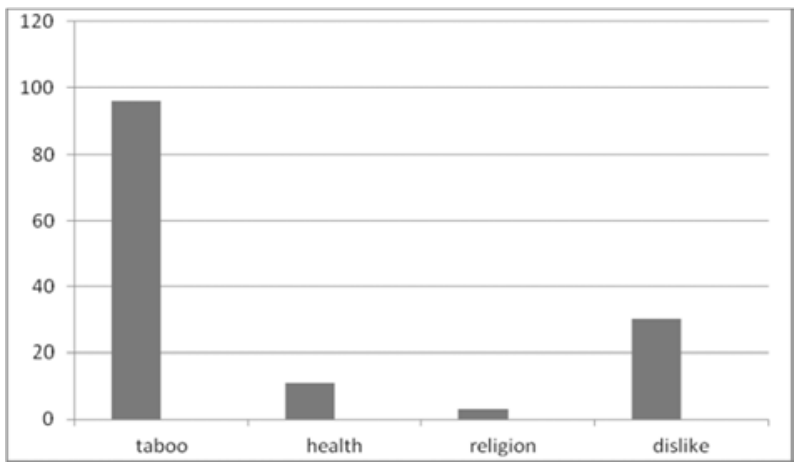

Figure 3. Reasons why respondents don't kill or consume some animal species in MCNP.

\section{Discussion}

Four major limitations affecting effective practice of taboos and norms identified include; intrusion of other tribes, westernization/religion, improved hunting technique (the use of sophisticated guns, traps, carbide-powered head lamps and torchlight) and poverty. These were seen as the main cause of non-compliance with norms and taboos leading to the fast decline in the Bakweri tradition. This study portrays a two-sided event in the use of traditional practices in the conservation of wildlife species in the study area. On the one hand, the result shows that the respondents appreciated and are aware of the impact of traditional practices that ensure the protection of wildlife species in the study area, and on the other hand, these belief/traditional practices are fast eroding and, if no prompt action is taken, they may disappear, with potential consequences for the survival of the species in the area.

Accordingly, Etiendem et al., 2011 also reported that when confronted with these circumstances, it is easy for conservationists to ignore the local belief systems and stick to the more contemporary systems, as it can be argued that traditional belief systems are losing ground and incorporating them into conservation strategy is meaningless as the beliefs will eventually disappear. Paradoxically most of the wildlife species prohibited from being hunted by taboo in the study area are listed in the IUCN 2010 red list as being highly threatened. Moreover, their remaining habitats are being 
isolated and highly fragmented rapidly. It has been emphasized that the survival of vulnerable wildlife population located outside protected areas will ultimately depend on the involvement of local communities living adjacent to these populations (Oates et al., 2004). In such a place, the conservation of these critical wildlife species urgently needs the support of the local communities and its traditional knowledge for its conservation (Nyhus et al, 2003), and as long as these cultural practices still exist, integrating them into conservation strategies is therefore paramount to the survival of these species they tend to protect. In all villages surveyed, although only a handful of wildlife species were considered as totem animals or as sacred animals, some wildlife species were forbidden to be killed or eaten. The presence of these taboos prohibiting the exploitation of these species has also been considered as a successful local conservation strategy (Colding and Folke, 2001; Banjo et al., 2006; Saj et al., 2006; Etiendem et al., 2011). However, considering its gradual erosion in the community, if not revived, the loss of respect for the beliefs and practices that led to the taboo is imminent. It is equally important to note that these taboos are currently still in place. The rejuvenation or establishment of new hunting bans will no doubt contribute to the protection of wild fauna and flora species in the study area. Today, government has created a national park which is protected by the law but this park lacks the kind of control and protection that existed within sacred traditional forests. Gone are those days where Chiefs and Fons in the South West and North West regions of Cameroon used to have strong and powerful authorities and sacred societies the Ekpe, the «Kwifon» the «Ngumbas» and the «Sambas» whose word was law and order at the same time (sources may be needed here). These institutions have lost some of their authority to the modern institutions of the State.

In traditional conservation systems, control is rooted deep inside the consciences of everyone and some of the fears of repercussions are so deep that no one dare go against any taboo, any law or regulation that is in place. Traditionally, wildlife was regarded as a valuable community asset, which was used and protected by customs and taboos. Taboos were of serious significance as some animals could not be killed or touched because of many reasons advanced which were wide and varied but invariably, cultural, spiritual and ancestral. This study yielded un-similar results to those of Ntiamoa Baidu, in Ghana, specifically in Boabeng and Fiema villages of the Brong Ahafo region, where the black and white colobus monkey and the mona monkey and their forest habitat have long been protected by the people because of their beliefs and traditions. They believe that the Black and white colobus are sons of gods protecting their community as the respect reserved for such a tall order equally goes with these monkeys who cannot be disturbed, killed or captured. The monkey is mourned and buried like a human being when it dies. This has attracted other species of monkeys into the area and little wonder this is the only place in Ghana where you still find large numbers of monkeys (source). The monkeys simply feel safe and secure there. This exemplifies the role African cultures played in conserving species from extinction. In the tradition of the study area they believe in life after death, the human culture is transformed or human spirit is transformed into animals and other objects. Most of the animals are considered spiritual. Take for example the lion, the leopard, the python, the buffalo and the elephant. These are royal animals which when seen anywhere represent the spirit of a deceased and cannot be shot or tampered with without the permission of the palace. There are also other animals in which people's spirits can live in the form of that animal and there are also traditions that prohibit the killing of these animals without prayers, rituals and without also finding out whether these are rare animals or spiritual animals. Remnants of this tradition exist today but they have almost totally fallen apart because of changes in the society. These changes are political, religious and social, which came as the western civilization came along. The result of these new cultures and new methods of wildlife exploitation have been the continuous decline in species of wildlife in MCNP. Although official statistics no longer present demographic information in terms of ethnic origin, Kofele-Kale (1981) noted that: " there were an estimated 17 immigrants to every native-born person in Fako Division and nearly 4 immigrants to every native Bakwerian in the native areas alone", today that number has increased more than 50 folds and has negative influence on the Bakweri culture and values.

Lyombe (2004) observed that it is no surprise that the Bakweri, have a secret society that venerates, imitates and personifies the attributes of the elephant. Indeed, those who belong to the "Maalé", the secret elephant society, swear by nothing other than Loxodonta Africana (the African elephant). The "Maale" which literally means (gathering of the villages') origins are lost in the fog of Bakweri mysticism. According to folklore, the Maalé society came out of the Nganya, a secret society whose job is to protect the village from evil. The female version of Maale has the warthog or wild boar as its mascot (Lyombe, 2004). According to Lyombe (2004), of the about 100 villages surrounding the Mount Cameroon National Park, the Maalé secret society survives in less than ten Bakweri villages because Christian missionaries who started missions in Bakweri land (Baptists, Catholics and Presbyterians) generally considered the Maalé and the Nganya heathen cult were sending their adherents straight to hell. The secret society did not survive in the villages in which mission stations were set up. Reasons as to why young men join the Maale society ranged from love of Bakweri culture to a desire for mystical protection from the forces of evil. Many of the members claimed to have elephants in the bush. Their lives had become one with the animals and their destinies were henceforth inherently linked. They make sure that elephants are not hunted for their ivory as has been the case in the past.

Colding and Folke (2001) presented a list of taboos across the globe which is strictly observed by pregnant women, which are basically for the health of the unborn child. This will normally discourage the hunting of such species. This may, 
however, not be an assurance for the conservation of the animals concerned as it gives room for commercial hunting of the species. This is in line with the submission of Kideghsho (2008) that some people may kill tabooed animals for commercial purpose. The elephant is also a taboo in some parts of Ghana and Ikoma tribe in Tanzania (Kideghsho, 2008; Nganje 2009). Kideghesho (2008) reported an example of such in Cameroon, where 29 species of animal are avoided by women due to the fear of losing their pregnancies. This sounds good for the conservation of such species; however, money incentive especially for the tusk of elephant can predispose it to killing even if not for food. The effectiveness of traditional institutions in conservation and protection of biodiversity has been reported in some parts of Nigeria (Anoliefo et al., 2003; Banjo et al., 2006; Obasohan, 2008; Akindele, 2010). Anoliefo et al. (2003) noted that cultural taboos and their sanctions have helped to check abuse of natural resources at least among the local people. It is also effective in some areas and has contributed to the conservation of biodiversity and wise use of resources in some parts of Ghana (Abayie- Boateng 1998; Sarfo-Mensah and Oduro, 2007; Kobina and Kofi, 2009). The success of traditional systems of resource conservation relies heavily on the presence of a homogenous ethnic or cultural community sharing similar values and experiences. This is usually based on a strong shared belief in the spiritual world and its pervasive influence on people's lives (Colding and Folke, 2001; Kobina and Kofi, 2009). The Bakweri tribe who are the custodian of these taboos blamed the killing of forbidden animals on strangers mainly from the other parts of Cameroon and some Nigerians whom they claim may not be aware of or choose not to obey the traditional taboos and customs. Similar situations have also been reported in other places (Mwihomeke et al., 1998; Mbotiji, 2002; Nganje, 2009; Saka et al., 2012). Taboos in the area also suffer a setback with the arrival of the carbide head lamp and torchlight, only the glows of animals' eyes are seen, with little or no time for the hunter to be sure of the animal species. Horowitz (1998) and Mbotiji (2002) also observed that improved technology in hunting is a big setback for effectiveness of taboos for resource conservation in many areas. Religion and westernization also play a role as many who belong to a western religion now see some of these taboos as being satanic (Horowitz, 1998; Mwihomeke et al., 1998; Mbotiji, 2002; Kobina and Kofi, 2009 and Nganje, 2009). Saj et al. (2006) reported a case in Ghana where the Saviour Church of Ghana, encouraged their members to hunt monkey which is a taboo among the people. This according to them affects the population of monkey. In Nigeria, Anoliefo et al. (2003) and Akindele (2010) reported that, many local people in Nigeria have embraced Christianity and hence shun traditional religion and its taboos. In view of democratic governance which guarantees basic freedom and human rights, many traditional rulers have lost their power over the villagers. Power is now vested in the political class which is largely dominated by the elites. They have therefore lost the power to enforce compliance with taboos within their domains.

\section{Conclusion}

Among the major conclusions of this paper, although the potential of traditional natural resource management for biodiversity conservation in Cameroon is huge, the sustainability of these practices is declining seriously and threatened. This stems from the rapid changes in the belief system with increased modernization, religious beliefs and poverty. Both biophysical and socio-economic factors were found to underlie these changes. The breakdown of traditional beliefs and associated taboos which strengthen traditional natural resource management practices were found to be the greatest threat to the sustainability of these practices. Some animals are forbidden, either due to cultural taboo, religious reasons, food taboo or on health grounds as seen in table 4 above. However, dwindling powers of traditional authorities and cultural erosion due to modernization and embracement of western religion; education and the advent of sophisticated hunting equipment and widespread poverty prevalence limit the efficiency of the application of these traditional conservation measures.

Nevertheless, adaptation of some aspects of these taboos may be valuable for wildlife conservation. However, they require institutional support to strengthen them to be more effective. It is pertinent that we manage these resources with the help of these traditional institutions now that they are still available and some animals are still in existence in the forest, or else, when the value of these taboos would be realized, it might be too late to achieve any meaningful success. The cultural transformation across the study area has questioned the validity and power of integrating cultural beliefs into the conservation agenda although holders of these knowledge systems remain a vital stakeholder in wildlife conservation, most especially in the unprotected forest. The people in the study area still appreciate and uphold their traditional beliefs regarding some wildlife species. However, the interest and support for such cultural practices is gradually eroded as these communities become more globalized with the advent of development and western education and religious proliferation. Thus, the loss of traditional knowledge concerning wildlife in this area is imminent as it could negatively impact on conservation in the area.

There is need for new and holistic wildlife conservation policies that will blend traditional systems of regulation, myths, rituals, and perception with existing wildlife legislation in the country to enhance conservation in Mount Cameroon National Park. Greater collaboration between conservationists/wildlife managers and traditional institutions (e.g., village councils) responsible for regulating and enforcing taboos where such taboos exists should be a core priority of conservation efforts in the country. Similarly, eleven wildlife species are forbidden, either due to cultural taboo, religious reasons, and personal dislike or on health grounds. However, dwindling powers of traditional authorities and cultural erosion due to modernization and embracement of western religion; advent of sophisticated hunting equipment and widespread poverty incidence limit 
the efficiency of the application of these traditional conservation measures. Nevertheless, adaptation of some aspects of these taboos may be valuable for wildlife conservation. However, they require institutional support to strengthen them to be more effective.

Finally, more anthropological research should investigate local perceptions of forest space and landscape, biodiversity conservation and traditional beliefs, and their significance for natural resources management. Such studies would provide valuable insights into the changing values of local people in relation to protected areas such as sacred groves and forest reserves and the management of other natural resources

\section{References}

[1] Abayie-Boaten, A. 1998. Traditional conservation practices: Ghana's example. In: DS Amlalo, LD Atsiatorme, Fiati (Eds.) Biodiversity Conservation: Traditional Knowledge and Modern Concepts. Paper presented at the Third UNESCOMAB Regional Seminar on Biosphere Reserves for Biodiversity Conservation and Sustainable Development in Francophone Africa (BRAAF), Cape Coast, 9 -12 March, 1998.

[2] Akindele, S. O. 2010. Forest Restoration through Traditional Institutions in Nigeria: Challenges and Prospects. From $<$ http://www.cfc 2010.org/papers/session13/Akindeles13. pdf $>$ (Retrieved August 27, 2011).

[3] Anoliefo, G. O., Isikhuemhen, O. S. and Ochije, N. R. 2003. Environmental implications of the erosion of cultural taboo practices in Awka-South Local Government Area of Anambra State, Nigeria. Journal of Agricultural and Environmental Ethics, 16: 281-296.

[4] Augustine Ngoni Monono - William Oduro · Paul SarfoMensah $\cdot$ Celestin Nana 2016. The Role of Bakweri Traditional Beliefs in the Management of Mount Cameroon National Park.

[5] Banjo, A. D., Otufale, G. A., Abatan, O. L. and Banjo, E. A. 2006. Taboo as a means of plant and animal conservation in South-Western Nigeria: A case study of Ogbe River and its Basin. World Applied Sc, 1: 39-43.

[6] Bassey, A. E., and Kanung, R. 1996a. A brief look at conservation ethic within the culture of people of Okwango. In: E. Obot, J. Barker (Eds.): Essential Partnership-The Forest and the People Paper presented at the Workshop on Rain Forest of South - Eastern Nigeria and South Western Cameroon held at Obudu Cattle Ranch and 21 Resort, Obanliku Local Government Area, Cross River State, Nigeria on 20th -24th October 1996.

[7] Bassey, A. E. and Kanung, R. 1996b. The history and cultural background of Busi people. In: E Obot, J Barker (Eds.): Essential Partnership- the Forest and the People. Paper presented at the Workshop on Rain Forest of South-Eastern Nigeria and South Western Cameroon held at Obudu Cattle Ranch and Resort, Obanliku Local Government Area, Cross River State, Nigeria on 20th -24th October 1996.

[8] Becker, C. D. And Ghimire, K. 2003. Synergy between traditional ecological knowledge and conservation science supports forest preservation in Ecuador. 8 (1): 1.

[9] Beckes CD, Ghimire K 2003. Synergy between Traditional
Ecological Knowledge and Conservation Science Supports Forest Preservation in Ecuador. Conserv Ecol, 8: 1. From (Retrieved 21 October 2010).

[10] Berkes, F., Colding, J. and Folke, C. 2000. Rediscovery of traditional ecological knowledge as adaptive management. 10 (5): $1251-1262$.

[11] Berkes, F. 2003. Rethinking community-based conservation. 18 (3): $621-630$.

[12] Caldecott, J., L. Mills, and C. Nelleman. 2005. Challenges to great ape survival. Pages 217 - 234 in J. Caldecott, and L. Mills, editors. World atlas of great apes and their conservation. University of California Press, Los Angeles, California, USA.

[13] Colding, J. and Folke, C. 2001. Social Taboos: 'Invisible' systems of local resource management and biological conservation. 11: 584 - 600. Eneji, C. V. O., Ntamu, G. U., Ben, C. B., Bassey, T. E. and Williams, J. J. 2012. "Ethical Basis of African traditional religion and socio-cultural practice in Cross River State Nigeria. Journal of research in peace, gender and development, 2 (2): 034-042.

[14] Etiendem, D. N., Hens, L. and Pereboom, Z. 2011. Traditional knowledge systems and the conservation of Cross River gorillas: a case study of Bechati, Fossimondi, Besali, Cameroon. Ecology and Society 16 (3) 22.

[15] Gadgil, M., Berkes, F. and Folke, C. 1993. Indigenous knowledge for biodiversity conservation. Ambio 22: $151-156$

[16] Hens, L. 2006. Indigenous knowledge and biodiversity conservation and management in Ghana. Journal of Human Ecology, 20 (1): 21-30.

[17] Hulme, D. and Murphree, M. 1999. Communities, wildlife and the 'new conservation' in Africa Journal of International Development, 11: 11-285.

[18] Horowitz, L. S. 1998. Integrating indigenous resource management with wildlife conservation: A case study of Batang Ai National Park, Sarawak, Malaysia. Human Ecology, 26: 371-403.

[19] Infield, M. and Adams, W. M. 1999. Institutional sustainability and community conservation: A case study from Uganda. Journal of International Development, 11: 305-315.

[20] Infield, M. 2002. Cultural values: A forgotten strategy for building community support for protected areas in Africa. Conservation Biology, 15: 800-802.

[21] Jimoh, S. O., Ikyaagba, E. T., Alarape, A. A., Obioha, E. E. and Adeyemi, A. A. 2012. The Role of Traditional Laws and Taboos in Wildlife Conservation in the Oban Hill Sector of Cross River National Park (CRNP), Nigeria. Journal of Human Ecology, 39 (3): 209-219.

[22] Jones, J. G., Andriamarovololona, M. M. and Hockley, N. 2008. The importance of taboos and social norms to conservation in Madagascar. Conservation Biology, 22: $976-$ 986.

[23] International Union for the Conservation of Nature (IUCN) 2010. IUCN red list of threatened species. IUCN, Gland, Switzerland. Kideghesho, J. R. 2008. Co-existence between the traditional societies and wildlife in Western Serengeti, Tanzania: Its relevance in contemporary wildlife conservation efforts. Biodiversity Conservation, 17: 1861-1881. 
[24] Kassilly, F. N. and Tsingalia, H. M. 2009. Persistence and loss of cultural values of Tiriki Sacred Groves in Hamisi District, Kenya: Implications for management (RH: Cultural Values of Tiriki Sacred Groves). J Hum Ecol, 27: 137-141.

[25] Kobina ED, Kofi AA 2009. Change and Continuity: Using Indigenous Knowledge to Achieve Environmental Sustainability in Ghana. Paper presented at the 7th International Science Conference on the Human Dimensions of Global Environmental Change held in Germany, Bonn, on 26th-30th April, 2009 on the Theme. The Social Challenges of Global Change. From (Retrieved, May 7 2017). Kweka, D. 2004. The Role of Local Knowledge and Institutions in the Conservation of Forest Resources in the East Usambara. Submitted to: UNESCO-Man and Biosphere (MAB) Young Scientist Programme.

[26] Lingard, M., Raharison, N., Rabakonandrianina, E., Rakotoarisoa, J. and Elmqvist, T. 2003. The role of local taboos in conservation and management of species: The radiated tortoise in Southern Madagascar: Conservation and Society, 1: 223-246.

[27] MINFOF and WWF 2014: The management plan of the Mount Cameroon National Park and its peripheral zone 20152019 E2326 V3.

[28] Moller, H., Berkes, F., Lyver, P. O. and Kislalioglu, M. 2004. Combining Science and Traditional Ecological Knowledge: Monitoring Populations for Co-management. Ecol Soc 9 (3).

[29] Mwihomeke, S. T., Msangi, T. H., Mabula, C. K., Ylhäisi, J. and Mndeme, K. C. H. 1998. Traditionally protected forests and nature conservation in the North Pare Mountains and Handeni District, Tanzania. J East Afr Nat Hist, 87: 279-290.

[30] Negi, C. S. 2010. The institution of taboo and the local resource management and conservation surrounding sacred natural sites in Uttarakhand, Central Himalaya. International Journal of Biodiversity and Conservation, 2: 186-195.

[31] Nganje, M. 2009. Harnessing Traditional Ecological Knowledge for the Conservation of Forests and biodiversity. XIII World Forestry Congress, Buenos Aires, Argentina, 1823 October 2009.

[32] Nkenze Mbonwoh 2010. Cameroon Buea - Mount Cameroon National Park Launched Copyright (C) 2010 Cameroon Tribune, cited in All Africa Media (retrieved May 7, 2017).

[33] Nvenakeng Suzanne Awung and Rob Marchant 2016. Investigating the Role of the Local Community as CoManagers of the Mount Cameroon National Park Conservation Project.Academic Editors: Yu-Pin Lin, Dirk S. Schmeller, Wei-Cheng Lo and Wan-Yu Lien

[34] Nyhus, P. J., Sumianto, and Tilson, R. 2003. Wildlife knowledge among migrants in southern Sumatra, Indonesia: implications for conservation. Environmental Conservation 30: $192-199$.
[35] Oates, J., Bergl, R. and Linder, J. 2004. Africa's Gulf of Guinea forests: biodiversity patterns and conservation Nigerian Journal of Agriculture, Food and Environment. 10 (2): 11-17.

[36] Obasohan, E. E. 2008. Fisheries biodiversity: The role of a traditional taboo/ritual prohibition in the management and conservation of the fish resources of Ibiekuma Stream in Ekpoma, Edo State, Nigeria. Bioscience Research Communications, 20: 257- 264.

[37] Ormsby, A. and Edelman, C. 2010. Community-Based Ecotourism at Tafi Atome Monkey Sanctuary, a Sacred Natural Site in Ghana. in Verschuuren, B. et al. (eds.) Sacred Natural Sites: Conserving Nature and Culture. London: Earth scan pp. 233-243.

[38] Peterson, M. N., Peterson, M. J., Peterson, T. R and Liu, J. 2007. A household perspective for biodiversity conservation. Journal of Wildlife Management, 1243-1248.

[39] Rabearivony, J., Fanameha I, E., Mampiandra, J. and Thorstrom, R. 2008. Taboos and social contracts: Tools for ecosystem management - lessons from the Manambolomaty Lakes RAMSAR site, western Madagascar. Madagascar Conservation and Development, 3: 7-16.

[40] Saj, T. L., Mather, C. and Sicotte, P. 2006. Traditional taboos in biological conservation: The case of Colobus vellerosus at the Boabeng-Fiema Monkey Sanctuary, Central Ghana. Soc Sci Inform, 45: 285-310.

[41] Sarfo-Mensah, P. and Oduro, W. 2007. Traditional Natural Resources Management Practices and Biodiversity Conservation in Ghana: A Review of Local Concepts and Issues on Change and Sustainability.

[42] Schachenmann, P. 2006. Spiritual values in Madagascar: The starting point for endogenous conservation initiatives. Mountain Research and Development, 26: 323-327.

[43] Tah Eric (2012) My Road To Democracy cited in The great apes organization Cameroon, LAGA wildlife law enforcement (retrieved May 7, 2017).

[44] Tako, C. 1999:. Local forest resource management systems (LFRMS) understanding, mobilization and monitoring. Sustainable wildlife management: West Coast area of Mount Cameroon.

[45] Tengo, M., Johansson, K., Rakotondrasoa, F., Lundberg, J. and Andriamaherilala, J. A. 2007. Taboos and forest governance: Informal protection of hot spot dry forest in Southern Madagascar. Ambio, 36 (8): 683-691.

[46] P. Sarfo-Mensah and W. Oduro 2007: Traditional Natural Resources Management Practices and Biodiversity Conservation in Ghana: A Review of Local Concepts and Issues on Change and Sustainability. 